Document downloaded from:

http://hdl.handle.net/10251/160440

This paper must be cited as:

Macian Martinez, V.; Tormos, B.; Ruiz-Rosales, S.; García-Barberá, A. (2019). An

Alternative Procedure to Quantify Soot in Engine Oil by Ultraviolet-Visible Spectroscopy.

Tribology Transactions. 62(6):1063-1071. https://doi.org/10.1080/10402004.2019.1645255

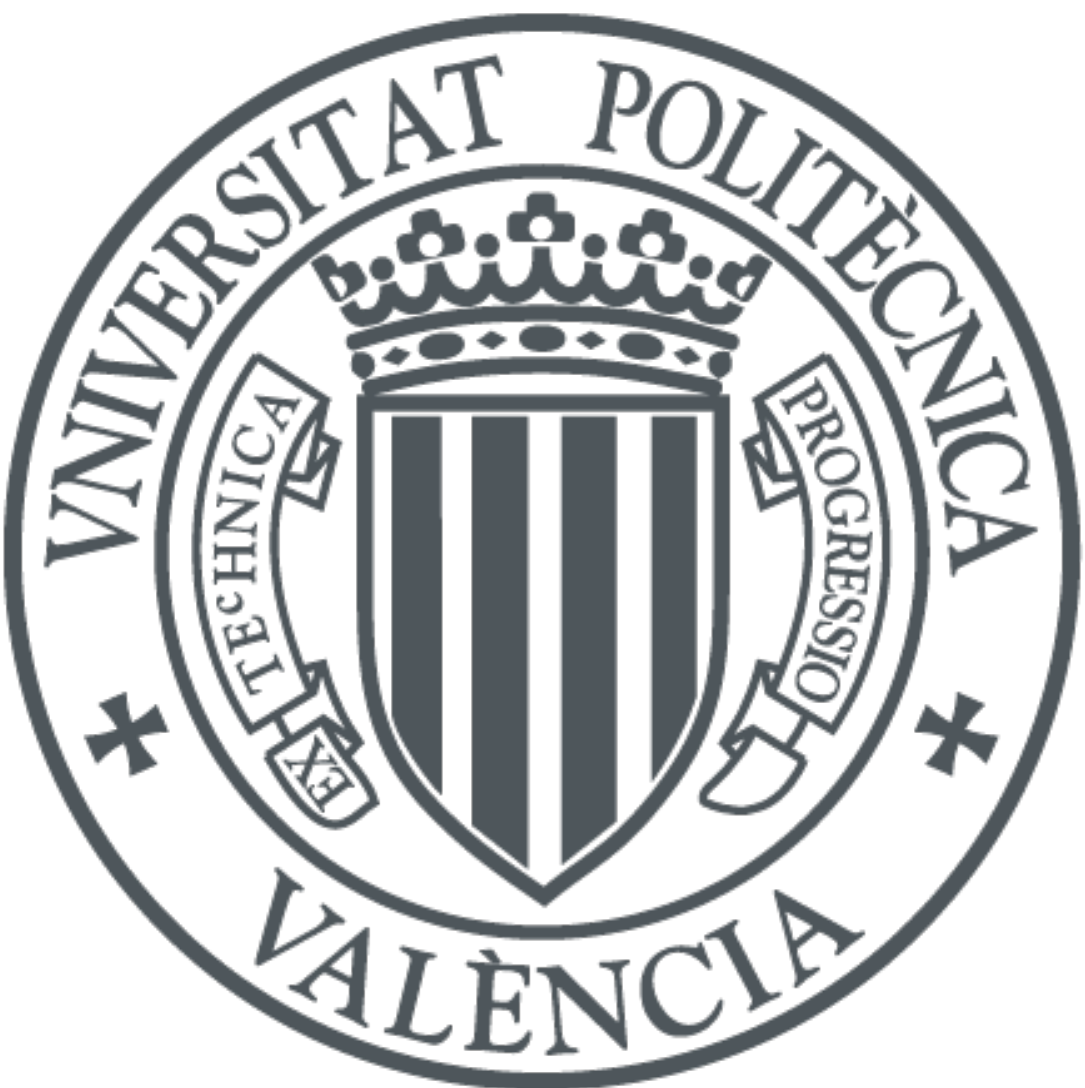

The final publication is available at

https://doi.org/10.1080/10402004.2019.1645255

Copyright Taylor \& Francis

Additional Information

"This is an Accepted Manuscript of an article published by Taylor \& Francis in Tribology Transactions on 02-11-2019, available online: https://www.tandfonline.com/doi/full/10.1080/10402004.2019.1645255." 


\title{
AN ALTERNATIVE PROCEDURE TO QUANTIFY SOOT IN ENGINE OIL BY ULTRAVIOLET-VISIBLE SPECTROSCOPY
}

\author{
Vicente Macián ${ }^{\text {a }}$, Bernardo Tormos ${ }^{\text {a }}$, Santiago Ruiz ${ }^{\text {a }}$, Antonio García-Barberá ${ }^{\text {a* }}$ \\ ${ }^{a}$ CMT- Motores Térmicos, Universitat Politécnica de València, Camino de Vera, 46022 \\ Valencia, Spain
}

*Corresponding author. Tel.: +34 963877 650. E-mail: angarba2@mot.upv.es (Antonio GarcíaBarberá)

\begin{abstract}
Internal combustion engines (ICE), as a consequence of new pollutant emissions standards, need several emission control strategies (and related procedures) such as Exhaust Gases Recirculation (EGR), Diesel/Gasoline Particulate Filter (DPF/GPF), Selective Catalyst Reduction (SCR) that allow them to comply with complete requirements defined on those standards. These strategies provoke faster degradation of the engine oil and one of the most relevant consequences is an increase in soot contamination level. All of these strategies facilitate the soot generation. Consequently, soot is one of the most important contaminants present in the engine oil and its relevance is still increasing. The main and classic technique to measure the content of soot in oil is Thermogravimetric analysis (TGA), but this technique has certain limitations. TGA needs a long specific procedure and has limitations to measure small concentration of soot in oil. Therefore, the design of an alternative technique to quantifying the soot in oil concentration is acquiring relevance. One alternative can be the Fourier-transform infra-red (FTIR) spectroscopy, but it also has limitations related to small concentrations of soot in oil. This work presents an alternative technique based on the Ultraviolet-Visible (UV-Vis) spectroscopy, which will let us to quantify
\end{abstract}


small soot contents in used engine oil samples and avoiding potential interferences from other typical contaminants or related with the own measurement process such as sample cuvette material.

\section{KEYWORDS}

Soot in oil, Soot quantification, UV-Vis

\section{INTRODUCTION}

Currently, engine oil suffers several adverse effects due to emission control strategies (1-6) and Diesel Particulate Filter (DPF) regeneration processes (7-10). In fact, new standards and regulations that define the amount of pollution that engines can exhaust into the atmosphere are more and more restrictive each year and the limits are lower (11-13). Consequently, internal combustion engines require more of these processes to be able to fulfil the mentioned standards. As a result, engine oil suffers damages such as faster thermal oxidation and/or nitration (14-17), combustion by-products contamination (unburned hydrocarbons (UHC) and soot) and fuel dilution $(18,19)$. Specifically, one of these combustion by-products is soot $(20,21)$. Soot in engine oil is an important contaminant because it changes its tribological performance. Mainly soot in engine oil leads to the following problems: it increases the engine oil kinematic viscosity (KV) (22) and increases engine wear attending that soot is an abrasive compound $(23,24)$. The global trend is that new engines are going to keep needing these strategies for pollutant emissions reduction and consequently the soot amount dissolved in engine oil will be an important factor to control.

Accurate quantification of soot in engine oil is thus of great interest. The main soot in oil quantification technique is TGA (thermogravimetric analysis or thermal gravimetric analysis) according to the Mack T-8 Engine Lubricant Test (ASTM D5967 Annex A4) (25, 26). 
Nonetheless, TGA analysis needs a specific procedure to determine the soot in oil concentration. As an alternative, the spectroscopy techniques have the advantage of being easier to use in the laboratory to develop engine oil analytical tasks.

Fourier-transform infra-red (FTIR) spectroscopy allows quantification of the soot in oil content and other engine oil contaminants and degradation patterns (27-29). However, focusing on the soot in oil quantification, the FTIR spectroscopy is not able to detect small variations of soot concentration in a reliable way. The reason for that is the complexity of the engine oil FTIR spectra, in several regions of the IR spectral window some absorption bands of different contributions appear and consequently, in the typical region where soot content is measured (ranging from $2000 \mathrm{~cm}^{-1}$ or $5000 \mathrm{~nm}$ ) (30) other bands can interfere and generate errors in the procedure for quantifying the soot concentration. For that reason, FTIR needs a complementary technique that lead to obtain quantifications in those conditions of change and without interferences (31).

According to the previous requirements, the Ultraviolet-Visible (UV-Vis) spectroscopy would be an interesting alternative (32). In general, for quantifying any analyte in a sample, UV-Vis spectroscopy is the most efficient technique being also very sensitive to slight changes in the concentration of the analyte $(33,34)$. Besides, if it works according to the Lambert-Beer conditions, it will be able to obtain easily a good correlation between the signal and the real concentration of the analyte.

Compared to FTIR spectroscopy, UV-Vis works similarly but with more intensive excitation radiation provides advantages for detecting and quantifying a specific analyte better than FTIR. Consequently, if the UV-Vis spectroscopy is specifically tuned to detect soot in oil, it will be able 
to generate a specific correlation between the signal response of the analysed sample and the amount of soot that contains.

\section{OBJECTIVES}

The main objectives of this study are presented below:

- Validation of the UV-Vis spectroscopy approach for accurate measurement of small soot in oil concentrations $(<0.500 \% \mathrm{w} / \mathrm{w})$.

- To establish the best spectral region in the UV-Vis spectrum for soot in oil quantification. Target will be to decide which is the spectral region where the signal is correlated uniquely with soot content without interference of other substances or contaminants.

- Analysis of real samples, previously characterized by FTIR, to check the accuracy of the UV-Vis spectroscopy against a very useful and developed technique such as the FTIR.

- To verify the applicability of the UV-Vis technique to quantify small soot in oil concentrations, real samples with very low periods of use will be analysed.

\section{METHODOLOGY AND MATERIALS}

\section{Main characteristics of UV-Vis spectrophotometer}

The UV-Vis spectrophotometer and the cuvettes employed for measuring the engine oil samples are presented in Table 1.

\section{[Table 1 here]}

Using double-beam spectrophotometer it is possible to analyse and meausre simultaneously the reference (solvent) and the sample for optimizing accuracy, sensitivity and reducing stray light.

\section{Measurement methodology}


The methodology of this study has been focused on the measurement of different types of samples to achieve different goals:

- First of all, it is necessary to define the best conditions to prepare the samples to obtain good signal responses. In general, the UV-Vis works with diluted samples. Consequently, two parameters are needed to take into consideration: solvent type and the concentration (dilution ratio) of the sample.

- After that, different fresh engine oil will be analysed and contaminated with typical external agents (contaminants) that can appear in real engine oil such as: soot, water, engine coolant or fuel. Therefore, the UV-Vis spectrum of each of them (engine oil and contaminants) can be obtained and consecutively obtain the distribution of its absorption bands. In this way, it will be possible to differentiate those UV-Vis regions that are not useful for soot quantification as a consequence of interference.

- Next, soot in oil standards will be measured to obtain an empirical correlation of UV-Vis signal-soot in oil concentration. In this part, it is necessary to work in Lambert-Beer law conditions to avoid non-linear responses.

- The following step will be to measure real samples with soot content previously measured by FTIR spectroscopy.

- Finally, the application of UV-Vis spectroscopy as technique to quantify small concentrations of soot in oil.

\section{Standards and engine oil samples}

Soot in oil standards are provided by LGC (a division of the LGC Group). Those soot in oil standards are made employing a 15W40 diesel engine oil as matrix and carbon black (CAS: 1333- 
86-4) as soot. The standards were prepared to the nominal concentration using gravimetric methods. The certified concentration was determined by Thermal Gravimetric Analysis (TGA) according to ASTM D5967 appendix A4. Six different standards have been used: $0.0 \%$ (Blank Oil), $1.2 \%, 3.1 \%, 5.1 \%, 7.6 \%$ and $10.1 \%$ ( $\pm 1 \%$ certified concentration by VHG Labs, part of LGC Standards).

Bearing in mind that one of the major goals is to detect small concentrations of soot in oil, the previous standards offer an overly high soot amount (by mass). Therefore, each standard was diluted with blank standard (Blank Oil, $0.000 \% \mathrm{w} / \mathrm{w}$ ) to reduce the soot concentration following the expression 1:

$$
\text { Soot conc.Final }(\% w / w)=\frac{\text { Soot conc. Initial }(\% w / w)}{\text { Dilution } \text { factor }}
$$

Another set of real oil samples were obtained from compression-ignition (CI), direct injection (DI) heavy-duty engine, with a displaced volume of 9 litres and 5 in-line cylinders. Furthermore, that engine possesses a common-rail injection system and turbocharged/intercooler water loop system. In this set, the soot content was measured by FTIR according to ASTM D7844. Selected real used engine oil samples are presented in Table 2. With the aim to check the response of the UV-Vis spectroscopy, each of the samples presented in Table 2 was diluted with its corresponding fresh engine oil. The last sets of samples are measured by UV-Vis spectrophotometer and were contrasted against the results of FTIR. Next, Table 2 presents all samples prepared for this study: standards and real engine oil samples.

[Table 2 here] 
Finally, another set of samples was selected to complete the study. This new set comprises six different samples obtained from a compression-ignition (CI), direct injection (DI) medium-duty diesel engine, with a displaced volume of 3 litres and 4 cylinders inline equipped with a commonrail injection system and a turbocharged/intercooler air loop system. This engine was mounted on a test bench and worked in a stationary point (55\% load, $2400 \mathrm{rpm}$ ) for 4 hours. Engine oil was sampled at different time intervals, but this low use period hampered the soot in oil quantification by common procedures. Figure 1 shows samples pictures and the period of use of the different samples obtained from the engine.

[Figure 1 here]

As can be observed in Figure 1, soot content can be related with sample colour ranging from clear appearance for 0 minutes usage (fresh oil) to quite dark after 240 minutes of usage, but in all cases, soot content is quite low considering the short period of usage.

\section{Methodology}

Considering the variety of engine oil samples, the preparation of the samples to be measured by UV-Vis can be probably the most important step. To prepare the samples it was necessary to determine several aspects: dilution ratio, solvent and the cuvette material.

Last parameter is the easiest one to select considering that our target is to maximise the UV-Vis spectrum without signals of the absorbance from the cuvette material. The cuvette selected was Spectrosil ${ }^{\circledR}$ Far UV Quartz windows with $10 \mathrm{~mm}$ of path length. The useful spectrum range of this cuvette range from $170 \mathrm{~nm}$ to $2700 \mathrm{~nm}$.

After that, the other two parameters are more difficult to determine. According to the characteristics of the engine oil samples, kerosene could be a good candidate to prepare an aliquot. 
Kerosene can dissolve all the samples and also allows to clean the cuvette easily. But selecting the correct dilution ratio is more difficult than the solvent. Figure 2 presents two different dilution ratios for the same sample (fresh Mid Saps 5W30 engine oil) prepared using micropipettes to take the specific volume accurately, first the engine oil volume and next the kerosene's volume (without doing consecutive dilutions to avoid making unnecessary experimental errors), to obtain the dilution ratio.

[Figure 2 near here]

According to the shape of the UV-Vis spectra, the red line (the most diluted sample) allows working without detector starvation (it means that the transmission is reaching a very low value, and as a result, the signal generated by the detector becomes practically constant). For the most concentrated sample (blue line) the appearance of tricks bands and noise can be observed. In that case, the analysed sample saturates the sensor and possibly leading to incorrect conclusions. Therefore, in the diluted sample (red line), the spectra show to be free of artifices demonstrating that higher dilution ratios are the most efficient way to measure by UV-Vis spectrophotometer.

However, this performance gives rise to the idea that could be possible to prepare samples with a higher dilution ratio, and therefore the analysis by UV-Vis spectroscopy would benefit. However, great care must be taken because the progressive reduction of the sample's amount lead to an exhaustive protocol to prepare it. And consequently, working with smaller sample volumes increase the complexity to prepare them, taking care of avoiding mistakes during the preparation.

Finally, a balance must be considered: on one hand, the dilution ratio employed in this study allows to obtain a good signal and on another hand, an easy procedure to prepare the solutions, taking 
into account, that it is only needed to employ two different micropipettes: one for taking the sample volume and another one for taking the kerosene volume, both of them with a single volume shot.

\section{RESULTS}

\section{Localization of the most useful spectrum zone}

The goal of this part of the study is the localization of the different components and contaminants that could affect the engine oil: soot, fuel, water and ethylene glycol (ETG) from the engine coolant. Not all of the above compounds are liquids, soot is a solid element and, in the defined conditions in section Methodology, do not possess absorption bands. In that case, the soot just impedes the passage of the UV-Vis radiation through the sample. That way, the absorbance of the sample is intense and it generates an increase of the spectra background.

[Figure 3 near here]

As it can be seen in Figure 3, engine oil, fuel, ETG and water generate absorption bands in the UV region (190-400 nm) and at Vis (visible) and NIR (near infra-red) region (from $600 \mathrm{~nm}$ to 1000 $\mathrm{nm}$ ) do not possess any band. However, the last region (from $1000 \mathrm{~nm}$ to $1400 \mathrm{~nm}$ ) will not be used because sometimes absorption bands generated by the cuvette material could appear and consequently affect the measurement.

According to the different performance of the compounds when irradiated with UV-Vis radiation, the first band (from $190 \mathrm{~nm}$ to $400 \mathrm{~nm}$ ) is not useful for soot quantifying because in those wavelengths appear the absorption bands of the different elements mentioned above. In a preliminary approximation, inside the spectral window of $700 \mathrm{~nm}$ to $900 \mathrm{~nm}$, it is possible to observe that no absorption exists because no bands appear. Consequently, the next step is to check 
the relation between the soot amount and the absorbance in this selected region (from $700 \mathrm{~nm}$ to $900 \mathrm{~nm})$.

\section{Soot in oil standards}

In the section 'Standards and engine samples' it was mentioned that the commercial standards should be diluted (see Table 2) to measure them in UV-Vis spectrophotometer. In Figure 4, it is possible to appreciate the results of some standards prepared by dilution with kerosene at 1/135 dilution ratio.

[Figure 4 near here]

The standards provided by LGC Standards possess soot levels which are too high. So high that the Std_3.100 $(3.1 \% \mathrm{w} / \mathrm{w})$ is able to absorb all the UV-Vis radiation. Therefore, if it is needed to quantify accurately soot in oil content, it would be necessary to dilute each of them with the Blank oil standard employing several dilution factors (as indicated in Table 2).

Performing this procedure and preparing the samples with the correct dilution ratio, the UV-Vis spectres are represented in Figure 5:

[Figure 5 here]

In this group of diluted samples is included the original soot in oil standard of $1.2 \% \mathrm{w} / \mathrm{w}$ (Std_1.200) because it does not surpass the limit of $3.1 \% \mathrm{w} / \mathrm{w}$. In this figure, attending the number of spectres depicted, it is not clear how to detect a correlation between the absorbance and the soot content. Accordingly, for a clearer observation of the measurement of samples with increasing soot in oil amounts, the response of the UV-Vis spectrophotometer is presented in Figure 6 . Observing these six diluted standards: Std_Blank $(0.000 \%$ w/w $)$, Std_0.025 $(0.025 \% \mathrm{w} / \mathrm{w})$, 
Std_0.050 $(0.050 \% \mathrm{w} / \mathrm{w})$, Std_0.100 $(0.100 \% \mathrm{w} / \mathrm{w})$, Std_0.150 $(0.150 \% \mathrm{w} / \mathrm{w})$ and Std_0.200 $(0.200 \% \mathrm{w} / \mathrm{w})$, in none of them occurs a starvation of the spectrophotometer detector and the absorbance of the standards (in $700 \mathrm{~nm}$ to $900 \mathrm{~nm}$ ) is below 1 absorbance unit (a.u.).

[Figure 6 here]

This figure allows extracting a correlation between the soot in oil concentration and standards's absorbance at $800 \mathrm{~nm}$ (in the middle of the selected spectral window, $700-900 \mathrm{~nm}$ ). The accuracy of the correlation is very good according to the value of its coefficient of determination $\left(\mathrm{R}^{2}\right)$ obtained: 0.99799 (see Figure 7).

The empirical correlation 2, according to the Lambert-Beer law, obtained is:

$$
y=1.41701 x-0.00209
$$

Where $\mathrm{y}$ is the absorbance of the diluted standards at $800 \mathrm{~nm}$ and $\mathrm{x}$ is the soot content.

Following that, employing the expression presented before (2), it is possible to obtain the soot in oil content for the dilted soot in oil standards.

[Figure 7 here]

In order to verify that the FTIR spectroscopy is able to quantify the different diluted standards before, all of them are measured by FTIR spectrophotometer according to the ASTM D7844. Soot in oil content of each of the diluted standards was obtained according to the dilution factor and the nominal value provided by LGC Standards (see equation 1) and later, this value is compared against the measured value (an average of triplicate analysis of each diluted standard). The results obtained through this procedure are presented in Table 3:

[Table 3 here] 
In Table 3, the final column shows the absolute percentage of differences, which are calculated employing the mathematical expression 3:

$$
\text { Percen. } \operatorname{diff}(\%)=\left|\frac{\text { FTIR }_{\text {Average }}-\text { Soot conc. }}{\text { Soot conc. }}\right| * 100
$$

Considering the results obtained, FTIR spectroscopy is useful to analyse engine oil samples with soot content between $0.100-2.000 \% \mathrm{w} / \mathrm{w}$. Outside this range, FTIR spectroscopy seems not to be a reliable technique, the results provided by this technique for small concentrations $(<0.050 \% \mathrm{w} / \mathrm{w})$ and higher concentration than $2.000 \% \mathrm{w} / \mathrm{w}$ were far from the expected value.

\section{Real samples}

Focusing on the first part of Table 3, if it is necessary to know the soot content for samples whose mileage is low (and consequently also soot concentration), the UV-Vis spectroscopy has enough resolution to measure this concentration.

This kind of samples is analysed following the same procedure employed for the soot in oil diluted standards. Because there were samples of different types of engine oil: Oil A (5W30), Oil B (5W30) and Oil C (10W40), the samples have been distributed in groups (see Figure 8).

[Figure 8 near here]

As can be observed in Figure 8, the samples present saturated bands in the region of $200-600 \mathrm{~nm}$ (according to own opacity that blocks the light to the detector). This effect can produce some errors when using the empirical correlation 2.

To minimize the starvation effect in the soot in oil quantification, samples were diluted by the addition of the equivalent mass of its corresponding fresh engine oil (as presented in Table 4). The results of the absorbance of the diluted samples are also shown in Table 4: 
[Table 4 here]

If it is compared the soot concentration (column number 2) obtained by FTIR, with the value obtained with UV-Vis spectroscopy (column number 4), the relation between both signals is good. Although it has been necessary to exclude sample 1_Oil_B (1_Oil_B, 1D_Oil_B and 2D_Oil_B) of this statement because the FTIR measures are not very reliable due to the soot content in all of them is below $<0.050 \%$ w/w. In Figure 9, the response of the UV-Vis versus the FTIR has been represented.

[Figure 9 near here]

The graph allows checking that when concentrations are higher than $\sim 0.500 \% \mathrm{w} / \mathrm{w}$ of soot in mass in engine oil, the empirical correlation 2 presents some limitations. But, if it takes into consideration that when the absorbance at $800 \mathrm{~nm}$ approaches to 1 a.u. (see Figure 10), the Lambert-Beer law cannot be fully applied since other contributions begin to appear meaning that the absorbance-concentration relationship will be not entirely linear. This is a requirement that is necessary to know for the applicability of the Lambert-Beer law. That is the reason why in Figure 9 a green dotted line appears to separate the samples that obey the Lambert-Beer law (left zone) and the samples that do not (right zone).

Now, using the samples that are in the left zone of Figure 9 and its dilutions, it is possible to measure their UV-Vis spectra with the security of not transgressing any of the requirements to apply the Lambert-Beer law. In Figure 10 all spectres of the samples with its corresponding dilutions are gathered.

[Figure 10 near here] 
The observed performance indicates that as long as none of the conditions of the Lambert-Beer law is violated, UV-Vis spectroscopy is able to provide similar values to FTIR spectroscopy.

\section{Low mileage samples}

Last but not least, main objective of this study is to check the applicability of UV-Vis spectroscopy as a technique capable of providing a reliable response of soot concentration when that concentration is very low $(<0.500 \% \mathrm{w} / \mathrm{w})$. Attending that, a sampling of low usage engine oils was carried out (see Figure 11). That samples has been taken from a diesel engine on a test bench, working on defined perameters of engine speed and engine load in order to assure a constant soot ratio generation.

\section{[Figure 11 near here]}

When these kinds of samples were measured by UV-Vis spectroscopy, measured at a 1/135 dilution ratio, none of them presented saturation spectrum problems. Thus, this is a justification that the sample preparation protocol is valid and useful. Moreover, there is a linear correlation between mileage (in minutes) and absorbance (at $800 \mathrm{~nm}$ ) of engine oil samples (Table 5).

[Table 5 near here]

When measuring the same samples with FTIR, due to its low concentration in soot, the device is not able to perform a reliable measurement.

\section{DISCUSSION AND CONCLUSIONS}

According to the results, the proposed alternative method based on UV-Vis spectroscopy is a potential technique to be applied for low soot in oil concentrations quantifying. Results obtained lead us to justify the performance of the UV-Vis spectroscopy when the amount of soot dissolved 
in the engine oil is lower than $0.500 \% \mathrm{w} / \mathrm{w}$. Consequently, this is an alternative to FTIR spectroscopy to quantify these low concentrations attending that in this range FTIR is not reliable and accurate.

This study has enabled to know the applicability of different techniques for quantifying soot in oil depending on expected soot concentration. In this way one gets to know which of the techniques: UV-Vis (below $0.500 \% \mathrm{w} / \mathrm{w}$ ), FTIR (from $0.500 \% \mathrm{w} / \mathrm{w}$ to $2.000 \% \mathrm{w} / \mathrm{w}$ ) and TGA (higher than $2.000 \% \mathrm{w} / \mathrm{w}$ ) are the best options according to the characteristics of the engine oil samples.

Furthermore, the ability of UV-Vis spectroscopy employing this model of work for detecting small soot content variations on engine oil, allows a significant reduction of engine bench test costs (time reduction) and an easy soot generation rate calculus.

\section{ACKNOWLEDGMENTS}

Antonio García-Barberá is supported through the Programa Nacional de Formación de Recursos Humanos de Investigación of Spanish Ministerio de Ciencia e Innovación [Grant Number BES016-078073].

\section{REFERENCES}

(1) L. L. F. Squaiella, C. A. Martins, P. T. Lacava (2013), "Strategies for emission control in diesel engine to meet Euro VI", Fuel 104, pp.183-193.

(2) W. Piock, G. Hoffmann, A. Berndorfer, P. Salemi, B. Fusshoeller (2011), "Strategies towards meeting future particulate matter emission requirements in homogeneous gasoline direct injection engines", SAE International Journal of Engines 4 (1), pp. 1455-1468. 
(3) B. T. Johnson (2008), "Diesel engine emissions and their control”, Platinum Metals Review 52 (1), pp. 23-37.

(4) T. V. Johnson (2009), "Diesel emission control in review”, SAE international journal of fuels and lubricants 1 (1), pp. 68-81.

(5) B. Mohan, W. Yang, S. kiang Chou (2013), "Fuel injection strategies for performance improvement and emissions reduction in compression ignition engines - a review", Renewable and Sustainable Energy Reviews 28, pp. 664-676.

(6) U. G. Alkemade, B. Schumann (2006), "Engines and exhaust after treatment systems for future automotive applications", Solid State Ionics 177 (26-32), pp. 2291-2296.

(7) S. Bensaid, C. Caroca, N. Russo, D. Fino (2011), "Detailed investigation of non-catalytic DPF regeneration”, The Canadian Journal of 430 Chemical Engineering 89 (2), pp. 401-407.

(8) Y. Kong, T. Kozakiewicz, R. Johnson, C. Huffmeyer, J. Huckaby, J. Abel, et al. (2005), “Active DPF regeneration for diesel engines", Tech. rep., SAE Technical Paper.

(9) R. Zhan, Y. Huang, M. Khair (2006), "Methodologies to control DPF uncontrolled regenerations", Tech. rep., SAE Technical Paper.

(10) E. Jiaqiang, L. Xie, Q. Zuo, G. Zhang (2016), "Effect analysis on regeneration speed of continuous regeneration-diesel particulate filter based on NO2-assisted regeneration", Atmospheric Pollution Research 7 (1), pp. 9-17.

(11) E. Directive, "Directive 2005/55/EC of the European Parliament and of the Council of 28 September 2005 on the approximation of the laws of the Member States relating to the measures to be taken against the emission of gaseous and particulate pollutants from compression-ignition 
engines for use in vehicles, and the emission of gaseous pollutants from positive-ignition engines fuelled with natural gas or liquefied petroleum gas for use in vehicles", Official Journal of the European Communities L 275 (2005) 1-163.

(12) E. Directive, "Regulation (EC) No 715/2007 of the European Parliament and of the Council of 20 June 2007 on type approval of motor vehicles with respect to emissions from light passenger and commercial vehicles (Euro 5 and Euro 6) and on access to vehicle repair and maintenance information", Official Journal of the European Communities L 171 (2007) 1-16.

(13) E. Regulation, "Regulation (EC) No 595/2009 of the European Parliament and of the Council of 18 June 2009 on type-approval of motor vehicles and engines with respect to emissions from heavy duty vehicles (Euro VI) and on access to vehicle repair and maintenance information and amending Regulation (EC) No 715/2007 and Directive 2007/46/EC and repealing Directives 80/1269/EEC, 2005/55/EC and 2005/78/EC", Official Journal of the European Communities L 188.

(14) A. Tripathi, R. Vinu (2015), "Characterization of thermal stability of synthetic and semisynthetic engine oils", Lubricants 3 (1), pp. 54-79.

(15) Ö. Karacan, M. Kök, U. Karaaslan (1999), "Dependence of thermal stability of an engine lubricating oil on usage period", Journal of thermal analysis and calorimetry 55 (1), pp. 109-114.

(16) J. A. Leet, T. Friesen, A. Shadbourne (1998), "EGR's effect on oi degradation and intake system performance", SAE transactions, pp. 347-354.

(17) J. Heredia-Cancino, M. Ramezani, M. Álvarez-Ramos (2018), "Effect of degradation on tribological performance of engine lubricants at elevated temperatures", Tribology International 124, pp. $230-237$. 
(18) D. Ljubas, H. Krpan, I. Matanović (2010), "Influence of engine oils dilution by fuels on their viscosity, ash point and fire point", Nafta: exploration, production, processing, petrochemistry 61 (2), pp. 73-79.

(19) M. Wattrus (2013), "Fuel property effects on oil dilution in diesel engines", SAE International Journal of Fuels and Lubricants 6 (3), pp. 794-806.

(20) V. Sharma, D. Uy, A. Gangopadhyay, A. O'Neill, W. A. Paxton, A. Sammut, et al. (2016), "Structure and chemistry of crankcase and exhaust soot extracted from diesel engines", Carbon 103, pp. 327-338.

(21) S. Pfau, A. La Rocca, E. Haffner-Staton, G. Rance, M. Fay, R. Brough, et al. (2018) "Comparative nanostructure analysis of gasoline turbocharged direct injection and diesel soot-inoil with carbon black", Carbon 139, pp. 342-352.

(22) S. George, S. Balla, V. Gautam, M. Gautam (2007), "Effect of diesel soot on lubricant oil viscosity", Tribology International 40 (5), pp. 809-818.

(23) S. Antusch, M. Dienwiebel, E. Nold, P. Albers, U. Spicher, M. Scherge (2010), "On the tribochemical action of engine soot”, Wear 269 (1-2), pp. 1-12.

(24) D. Green, R. Lewis (2008), “The effects of soot-contaminated engine oil on wear and friction: a review", Proceedings of the Institution of Mechanical Engineers, Part D: Journal of Automobile Engineering 222 (9), pp. 1669-1689.

(25) ASTM D5967-17 “Standard Test Method for Evaluation of Diesel Engine Oils in T-8 Diesel Engine”, Tech. rep., ASTM International (2017). URL https://doi.org/10.1520/D5967-17 
(26) A. Bredin, A. V. Larcher, B. J. Mullins (2011), “Thermogravimetric analysis of carbon black and engine soot - towards a more robust oil analysis method", Tribology international 44 (12), pp. $1642-1650$.

(27) ASTM D2412-10 "Standard Practice for Condition Monitoring of In-Service Lubricants by Trend Analysis Using Fourier Transform Infrared (FT-IR) Spectrometry", Tech. rep., ASTM International (2018). URL https://doi.org/10.1520/E2412-10R18

(28) F. Van De Voort, J. Sedman, R. Cocciardi, D. Pinchuk (2006), "FTIR condition monitoring of in-service lubricants: ongoing developments and future perspectives", Tribology Transactions 49 (3), pp. 410-418.

(29) F. R. Van De Voort, A. Ghetler, D. L. García-González, Y. D. Li (2008), "Perspectives on quantitative mid-FTIR spectroscopy in relation to edible oil and lubricant analysis: evolution and integration of analytical methodologies”, Food Analytical Methods 1 (3), pp. 153-163.

(30) ASTM D7844-18 "Standard Test Method for Condition Monitoring of Soot in In-Service Lubricants by Trend Analysis using Fourier Transform Infrared (FT-IR) Spectrometry", Tech. rep., ASTM International (2018). URL https://doi.org/10.1520/D7844-18

(31) M. Ess, D. Ferry, E. Kireeva, R. Niessner, F.-X. Ouf, N. Ivleva (2016), "In situ Raman microspectroscopic analysis of soot samples with different organic carbon content: Structural changes during heating", Carbon 105, pp. 572-585.

(32) C. Russo, B. Apicella, J. Lighty, A. Ciajolo, A. Tregrossi (2017), “Optical properties of organic carbon and soot produced in an inverse diffusion flame", Carbon 124, pp. 372-379. 
(33) H.-H. Perkampus (2013), "UV-VIS Spectroscopy and its Applications”, Springer Science \& Business Media.

(34) J. Workman Jr, A. Springsteen (1998), “Applied spectroscopy: a compact reference for practitioners", Academic Press.

\section{NOMENCLATURE}

\section{List of Symbols}

\begin{tabular}{|l|l|}
\hline ICE & Internal combustion engines \\
\hline EGR & Exhaust Gases Recirculation \\
\hline GDF & Diesel Particulate Filter \\
\hline SCR & Gasoline Particulate Filter \\
\hline CI & Selective Catalyst Reduction \\
\hline DI & Compression-ignition \\
\hline TGA & Direct injection \\
\hline FTIR & Thermogravimetric analysis \\
\hline$U V-V i s$ & Fourier-transform infra-red spectroscopy \\
\hline$U H C$ & Ultraviolet-Visible spectroscopy \\
\hline KV & Unburned hydrocarbons \\
\hline$I R$ & Kinematic Viscosity \\
\hline ETG & Infra-red \\
\hline
\end{tabular}




\begin{tabular}{|l|l|}
\hline UV & Ultraviolet \\
\hline Vis & Visible \\
\hline NIR & Near infra-red \\
\hline
\end{tabular}


TABLES AND FIGURES

\begin{tabular}{ll}
\hline \multicolumn{1}{c}{ Feature type } & \multicolumn{1}{c}{ Value or property } \\
\hline Lamp & Deuterium (D) and Tungsten Halogen (WI) \\
Beam & Double-beam \\
Spectral range (nm) & $1400-190$ \\
Scan (nm/min) & 400 \\
Cuvette material & Quartz \\
Path length (mm) & 10 \\
Table 1: Main features of the UV-Vis spectrophotometer and its cuvettes.
\end{tabular}

\begin{tabular}{|c|c|c|c|c|c|}
\hline Sample ID & Type & $\begin{array}{c}\text { Soot conc. } \\
\text { initial } \\
(\% \mathrm{w} / \mathrm{w})\end{array}$ & $\begin{array}{l}\text { Dilution } \\
\text { factor }\end{array}$ & $\begin{array}{c}\text { Soot conc. } \\
\text { final } \\
(\% \mathrm{w} / \mathrm{w})\end{array}$ & $\begin{array}{c}\text { Measurement } \\
\text { technique }\end{array}$ \\
\hline Std_Blank & Standard & 0.000 & - & 0.000 & TGA \\
\hline Std_0.025 & Standard & 1.200 & 48 & 0.025 & TGA \\
\hline Std_0.050 & Standard & 1.200 & 24 & 0.050 & TGA \\
\hline Std_0.100 & Standard & 1.200 & 12 & 0.100 & TGA \\
\hline Std_0. 0.150 & Standard & 1.200 & 8 & 0.150 & TGA \\
\hline Std_0.200 & Standard & 1.200 & 6 & 0.200 & TGA \\
\hline Std_ 0.240 & Standard & 1.200 & 5 & 0.240 & TGA \\
\hline Std_0.388 & Standard & 3.100 & 8 & 0.388 & TGA \\
\hline Std_0. 0.564 & Standard & 3.100 & 5.5 & 0.564 & TGA \\
\hline Std_0.775 & Standard & 3.100 & 4 & 0.775 & TGA \\
\hline Std_1. 1.086 & Standard & 7.600 & 7 & 1.086 & TGA \\
\hline Std_1.200 & Standard & 1.200 & 1 & 1.200 & TGA \\
\hline Std_1.347 & Standard & 10.100 & 7.5 & 1.347 & TGA \\
\hline Std_1. 1.520 & Standard & 7.600 & 5 & 1.520 & TGA \\
\hline Std_1.683 & Standard & 10.100 & 6 & 1.683 & TGA \\
\hline Std_1.855 & Standard & 5.100 & 2.75 & 1.855 & TGA \\
\hline Std_2.020 & Standard & 10.100 & 5 & 2.020 & TGA \\
\hline Std_2.267 & Standard & 5.100 & 2.25 & 2.267 & TGA \\
\hline Std 2.533 & Standard & 7.600 & 3 & 2.533 & TGA \\
\hline Std_2.914 & Standard & 5.100 & 1.75 & 2.914 & TGA \\
\hline Std 3.100 & Standard & 3.100 & 1 & 3.100 & TGA \\
\hline 1_Oil_B & Real samples & 0.054 & 1 & 0.054 & FTIR \\
\hline 2_Oil_A & Real samples & 0.199 & 1 & 0.199 & FTIR \\
\hline 3_Oil_A & Real samples & 0.302 & 1 & 0.302 & FTIR \\
\hline 4_Oil_B & Real samples & 0.406 & 1 & 0.406 & FTIR \\
\hline 5_Oil_C & Real samples & 0.473 & 1 & 0.473 & FTIR \\
\hline 6_Oil_C & Real samples & 0.607 & 1 & 0.607 & FTIR \\
\hline 7_Oil_C & Real samples & 0.700 & 1 & 0.700 & FTIR \\
\hline 8_Oil_A & Real samples & 0.873 & 1 & 0.873 & FTIR \\
\hline 9_Oil_B & Real samples & 1.000 & 1 & 1.000 & FTIR \\
\hline
\end{tabular}




\begin{tabular}{cccccc} 
10_Oil_C & Real samples & 1.263 & 1 & 1.263 & FTIR \\
\hline 1D_Oil_B & Diluted real samples & 0.054 & 4 & 0.018 & FTIR \\
2D_Oil_B & Diluted real samples & 0.054 & 2 & 0.027 & FTIR \\
3D_Oil_A & Diluted real samples & 0.199 & 4 & 0.066 & FTIR \\
4D_Oil_A & Diluted real samples & 0.199 & 2 & 0.099 & FTIR \\
5D_Oil_A & Diluted real samples & 0.302 & 4 & 0.101 & FTIR \\
6D_Oil_B & Diluted real samples & 0.406 & 4 & 0.135 & FTIR \\
7D_Oil_A & Diluted real samples & 0.302 & 2 & 0.151 & FTIR \\
8D_Oil_C & Diluted real samples & 0.473 & 4 & 0.158 & FTIR \\
9D_Oil_C & Diluted real samples & 0.607 & 4 & 0.202 & FTIR \\
10D_Oi1_B & Diluted real samples & 0.406 & 2 & 0.203 & FTIR \\
11D_Oil_C & Diluted real samples & 0.700 & 4 & 0.233 & FTIR \\
12D_Oil_B & Diluted real samples & 0.473 & 2 & 0.236 & FTIR \\
13D_Oil_A & Diluted real samples & 0.873 & 4 & 0.291 & FTIR \\
14D_Oi1_C & Diluted real samples & 0.607 & 2 & 0.303 & FTIR \\
15D_Oil_B & Diluted real samples & 1.000 & 4 & 0.333 & FTIR \\
16D_Oil_C & Diluted real samples & 0.700 & 2 & 0.350 & FTIR \\
17D_Oil_C & Diluted real samples & 1.263 & 4 & 0.421 & FTIR \\
18D_Oil_A & Diluted real samples & 0.873 & 2 & 0.436 & FTIR \\
19D_Oil_B & Diluted real samples & 1.000 & 2 & 0.500 & FTIR \\
20D_Oil_C & Diluted real samples & 1.263 & 2 & 0.631 & FTIR \\
\hline
\end{tabular}

Table 2: Set of samples. The first group is the standards that were employed to obtain the empirical correlation. The next set comprises samples from diesel engine oil, and the last one comprises the diluted samples from the diesel engine oil.

\begin{tabular}{|c|c|c|c|c|c|c|}
\hline \multirow{2}{*}{$\begin{array}{c}\text { Soot in } \\
\text { oil standard }\end{array}$} & \multirow{2}{*}{$\begin{array}{c}\text { Soot } \\
\text { concentration } \\
(\% \mathrm{w} / \mathrm{w})\end{array}$} & \multicolumn{4}{|c|}{ FTIR test } & \multirow{2}{*}{$\begin{array}{c}\text { Abs. } \\
\text { Percentage } \\
\text { difference }(\%)\end{array}$} \\
\hline & & Rep. 1 & Rep. 2 & Rep. 3 & Average & \\
\hline Std_Blank & 0.000 & 0.031 & 0.038 & 0.027 & 0.032 & - \\
\hline Std_-0.025 & 0.025 & 0.051 & 0.042 & 0.061 & 0.051 & 105 \\
\hline Std 0.050 & 0.050 & 0.053 & 0.080 & 0.072 & 0.068 & 37 \\
\hline Std 0.100 & 0.100 & 0.101 & 0.106 & 0.121 & 0.109 & 9 \\
\hline Std_0.150 & 0.150 & 0.148 & 0.156 & 0.192 & 0.165 & 10 \\
\hline Std_-0.200 & 0.200 & 0.200 & 0.214 & 0.221 & 0.212 & 6 \\
\hline Std_0. 0.240 & 0.240 & 0.275 & 0.262 & 0.215 & 0.251 & 4 \\
\hline Std_0.388 & 0.388 & 0.413 & 0.431 & 0.421 & 0.422 & 9 \\
\hline Std_0. 0.564 & 0.564 & 0.590 & 0.578 & 0.607 & 0.592 & 5 \\
\hline Std_0.775 & 0.775 & 0.764 & 0.730 & 0.796 & 0.763 & 2 \\
\hline Std_1.086 & 1.086 & 1.219 & 1.143 & 1.160 & 1.174 & 8 \\
\hline Std_1. 1.200 & 1.200 & 1.199 & 1.216 & 1.206 & 1.207 & 1 \\
\hline Std_1.347 & 1.347 & 1.590 & 1.549 & 1.521 & 1.553 & 15 \\
\hline Std_1.520 & 1.520 & 1.565 & 1.571 & 1.545 & 1.560 & 3 \\
\hline Std_1.683 & 1.683 & 1.728 & 1.715 & 1.700 & 1.714 & 2 \\
\hline Std_1.855 & 1.855 & 1.659 & 1.700 & 1.652 & 1.670 & 10 \\
\hline Std 2.020 & 2.020 & 2.186 & 2.222 & 2.199 & 2.202 & 9 \\
\hline
\end{tabular}




\begin{tabular}{lllllll} 
Std_2.267 & 2.267 & 1.960 & 1.897 & 1.937 & 2.034 & 15 \\
Std_2.533 & 2.533 & 1.905 & 1.893 & 1.929 & 2.125 & 25 \\
Std_2.914 & 2.914 & 2.250 & 2.281 & 2.277 & 2.491 & 22 \\
\hline
\end{tabular}

Table 3: Standards measured by FTIR to obtain the difference between TGA and FTIR measurements. Std_3.100 does not appear in this table because it could not be measured by FTIR.

\begin{tabular}{cccc}
\hline Sample ID & Usage (min) & Abs. $@ 0800 n m($ a.u.) & Calc. soot conc. $(\% \mathbf{w} / \mathbf{w})$ \\
\hline 1 & 0 & $0.001(3)$ & $0.002(4)$ \\
2 & 15 & $0.001(6)$ & $0.002(6)$ \\
3 & 30 & $0.002(0)$ & $0.002(9)$ \\
4 & 45 & $0.002(4)$ & $0.003(1)$ \\
5 & 60 & $0.002(7)$ & $0.003(4)$ \\
6 & 240 & $0.005(6)$ & $0.005(5)$ \\
\hline \multicolumn{4}{l}{ Table 4: Soot in oil concentration calculated by empirical correlation. }
\end{tabular}

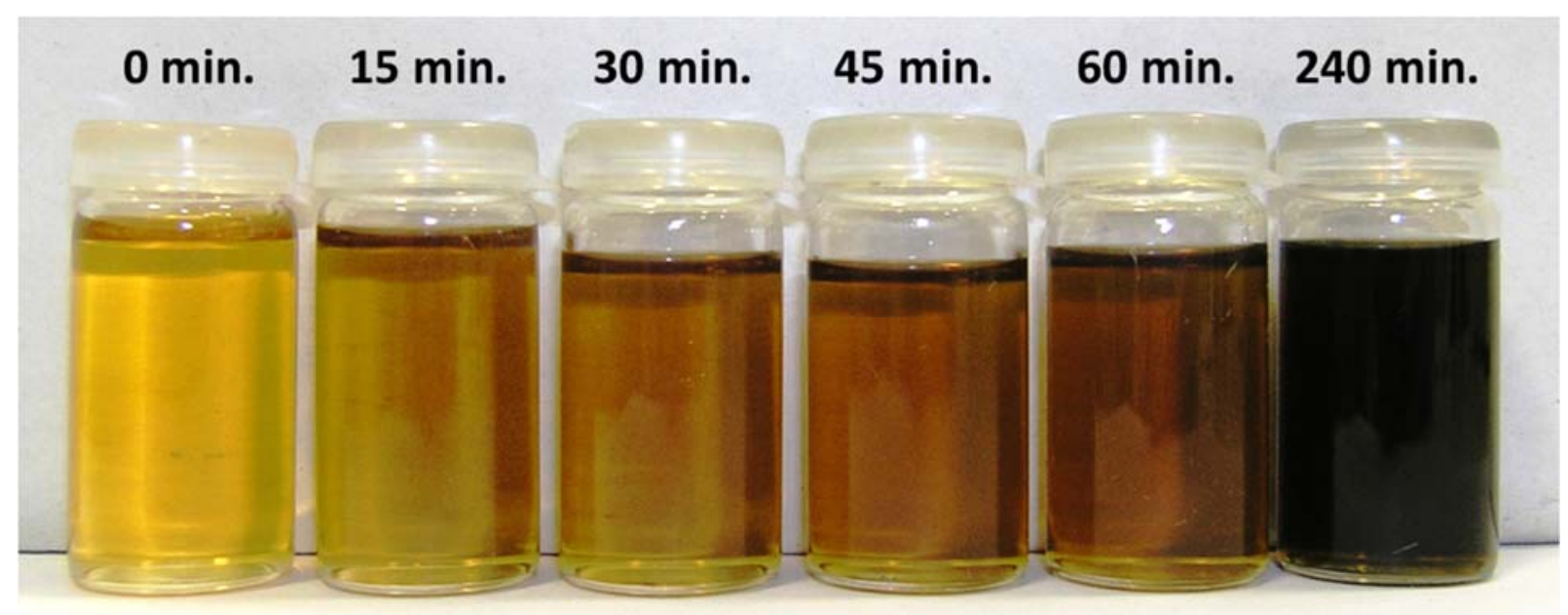

\begin{tabular}{cc}
\hline Sample ID & Usage (minutes) \\
\hline 1 & 0 (fresh oil) \\
2 & 15 \\
3 & 30 \\
4 & 45 \\
5 & 60 \\
6 & 240 \\
\hline
\end{tabular}

Figure 1: Real diesel engine oil samples with low period of usage. 


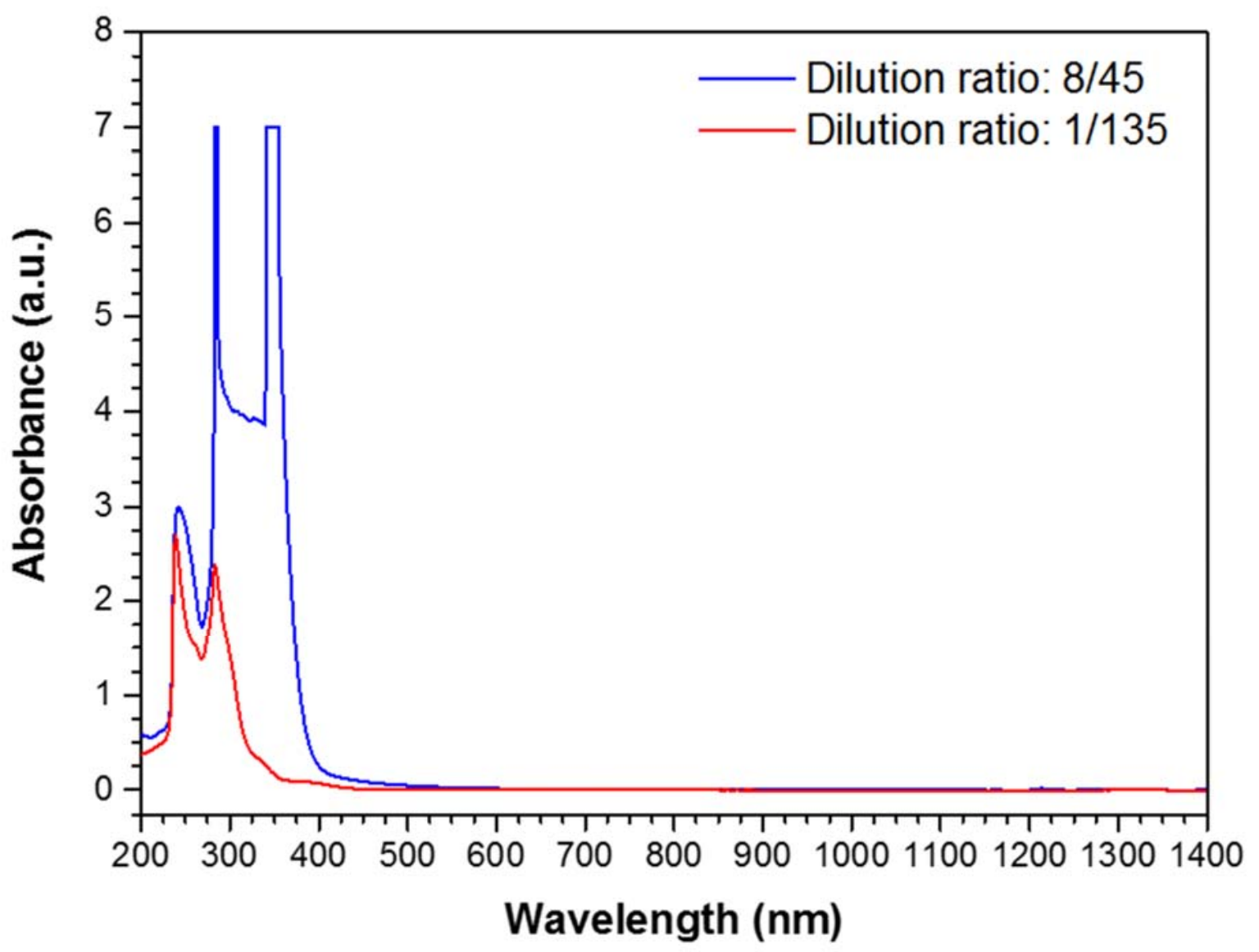

Figure 2: Tests to study the importance of the dilution ratio in the signal recorded in the spectrophotometer. In this tests, it has been employed fresh engine oil diluted with kerosene at two different ratios: $8 / 45$ and $1 / 135$. 


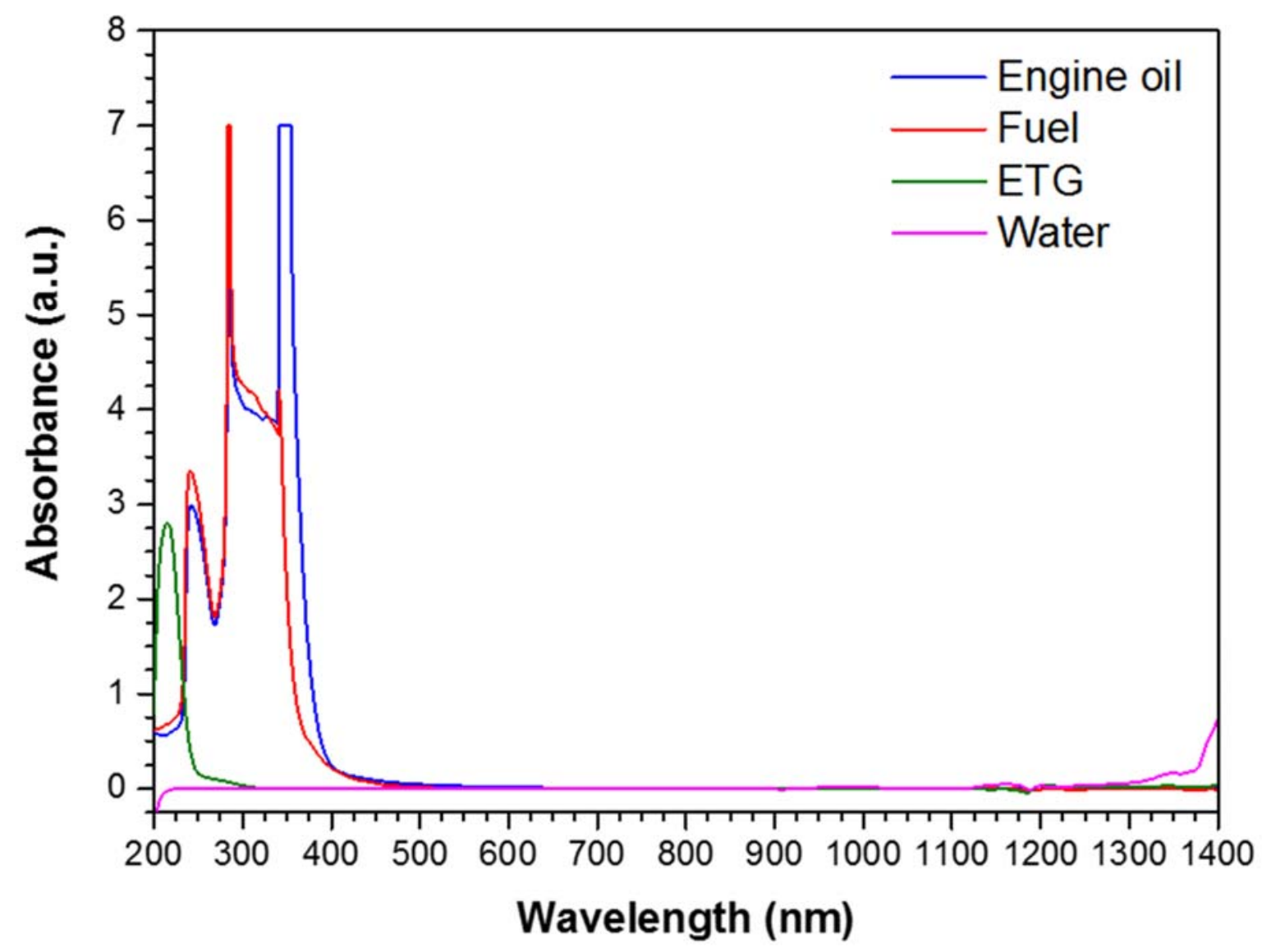

Figure 3: UV-Vis spectra of the different elements that can appear in the engine oil. With these results, it is possible to obtain the response of each of them and determinate the spectral window that is not useful to quantify the soot content. 


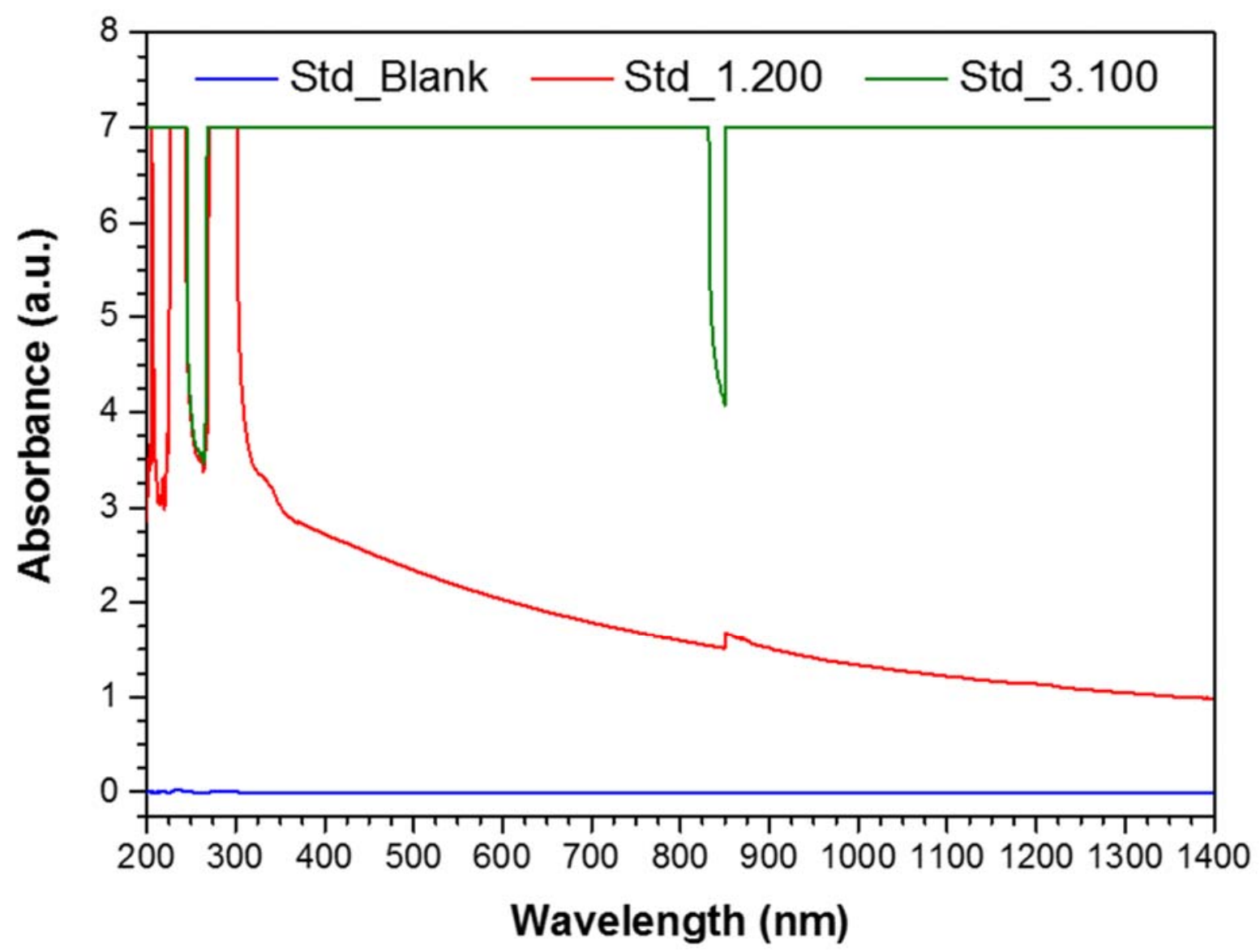

Figure 4: UV-Vis spectra of original soot in oil standards. These results are obtained measuring the standards in $1 / 135$ dilution ratio. The soot content in these standards provokes saturation of the detector, for this reason, it is necessary to employ standards with less soot concentration. 


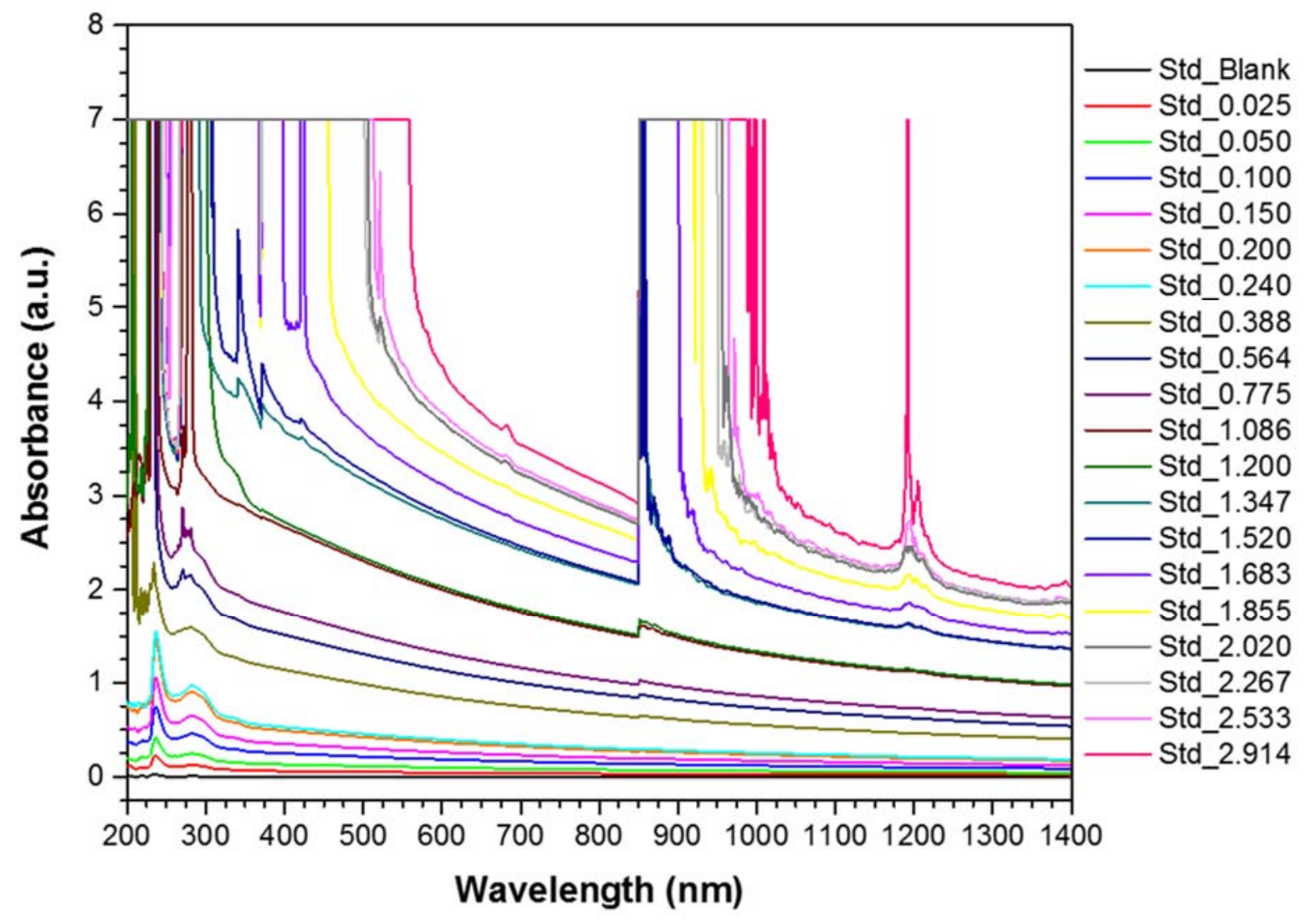

Figure 5: UV-Vis spectra of diluted original soot in oil standards. All of these are prepared according to its nomenclature: 'standard of origin' - 'times that its soot concentration has been reduced'. 


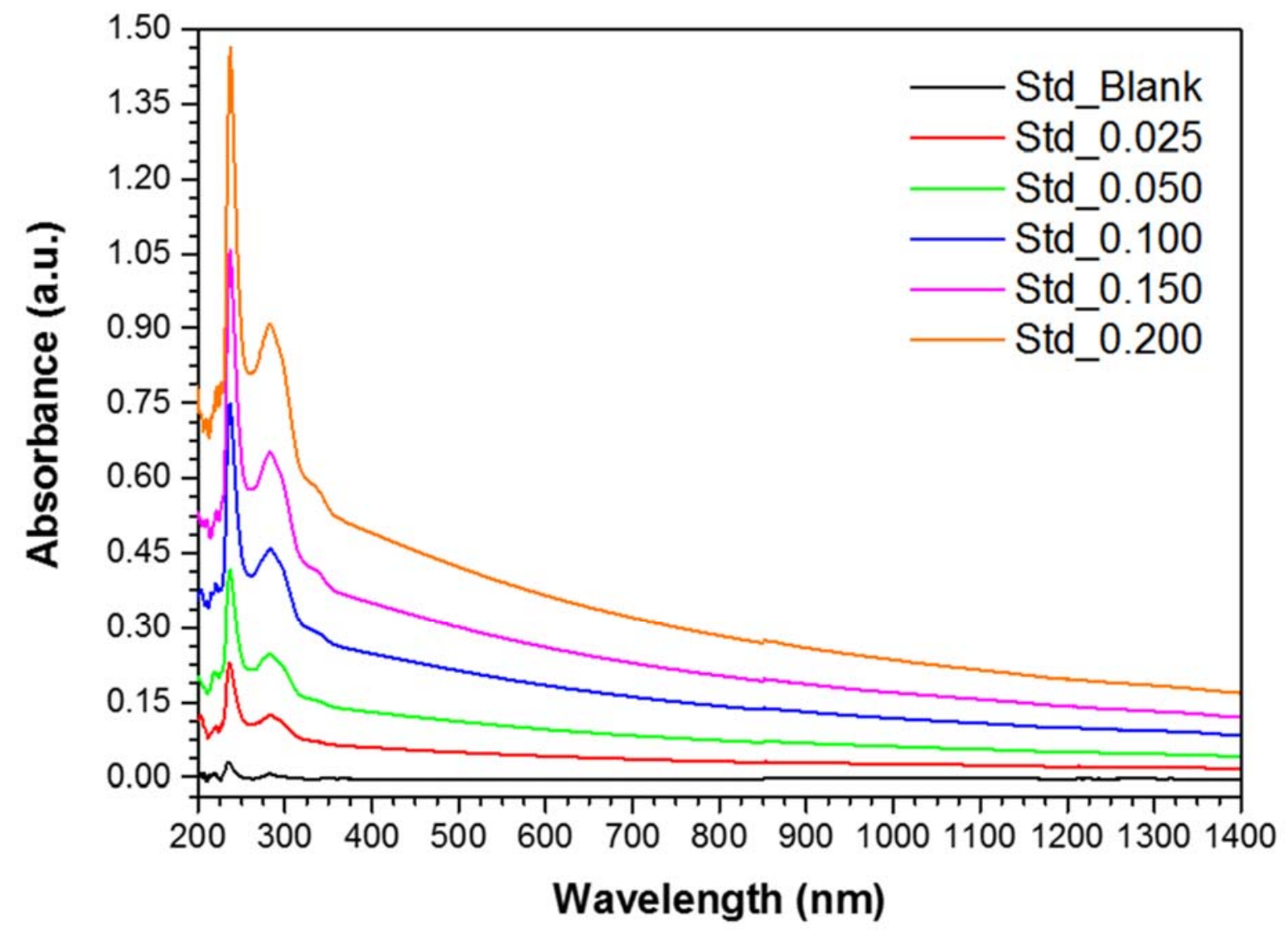

Figure 6: Selection of UV-Vis spectra of diluted soot in oil standards. These six standards do not saturate the sensor of the spectrophotometer. Consequently, it is possible to use them to generate a calibration curve. 


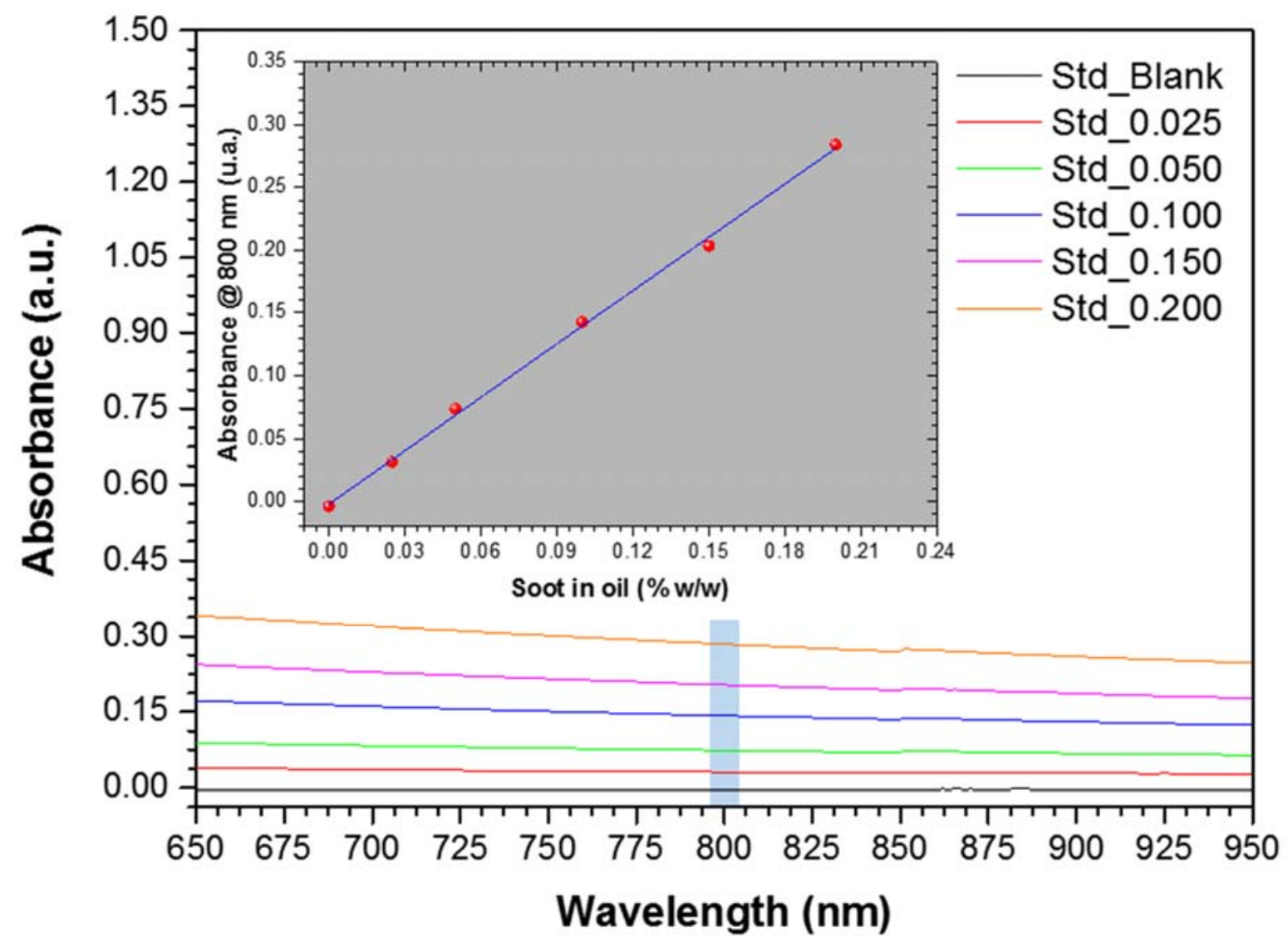

Figure 7: Correlation of soot in oil content of selected diluted standards with its absorbance at $800 \mathrm{~nm}$. 


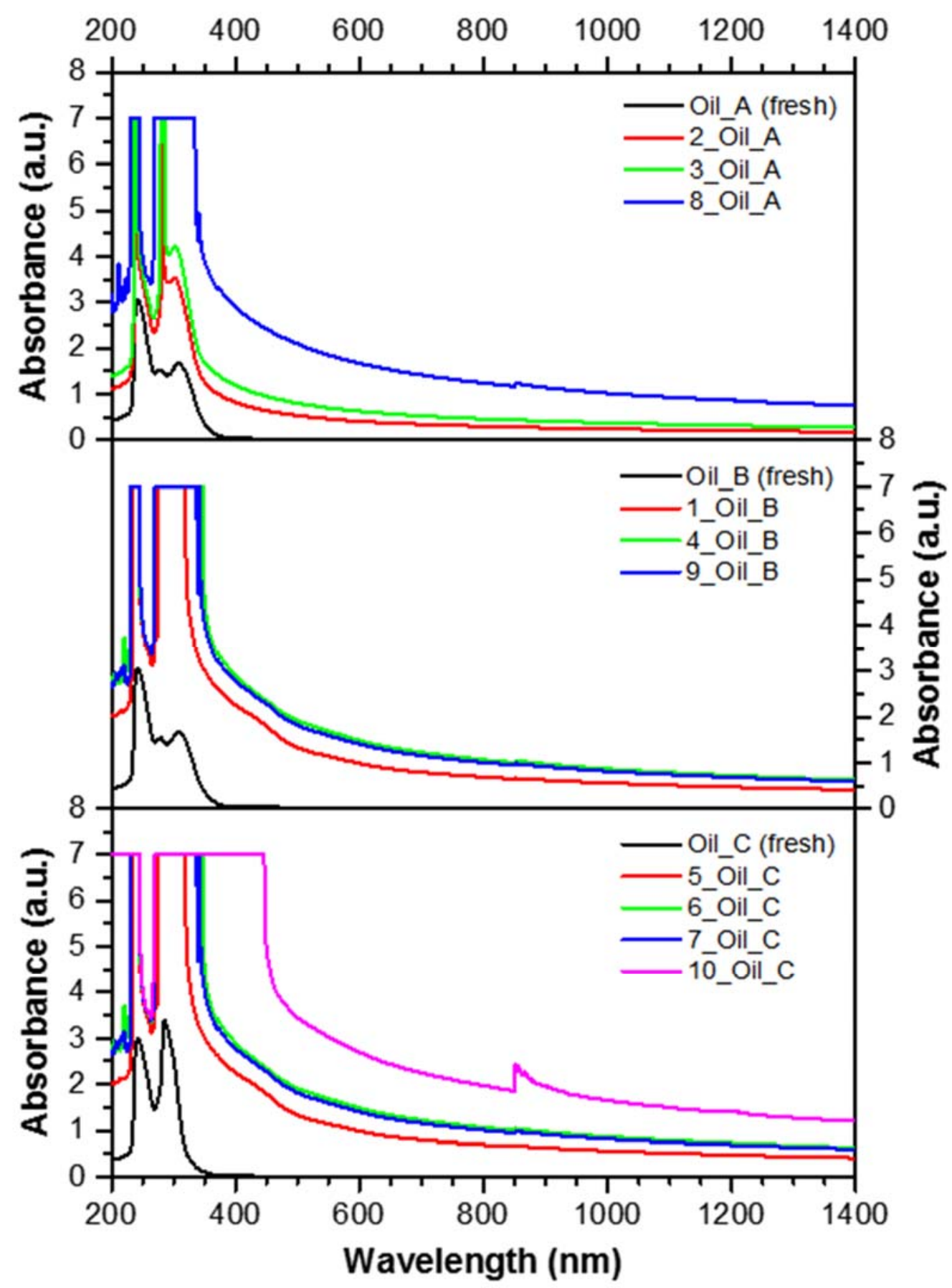

Figure 8: UV-Vis spectra of diesel engine oil samples. All these samples were prepared at a $1 / 135$ diluted ratio. 


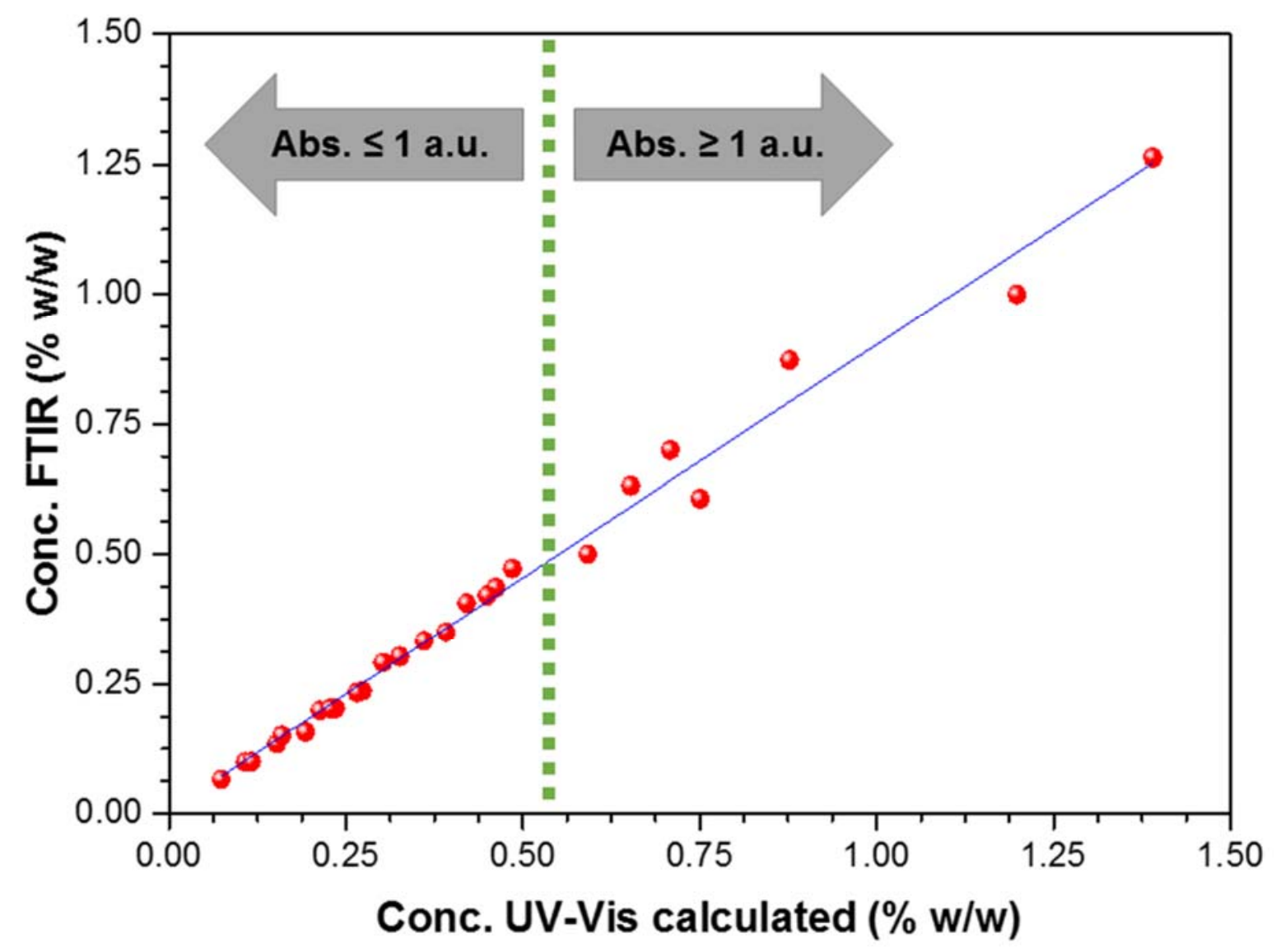

Figure 9: UV-Vis response against FTIR. The value of soot concentration by FTIR was obtained according to the standard ASTM D7844 and the UV-Vis values are calculated by the empirical correlation 2. 


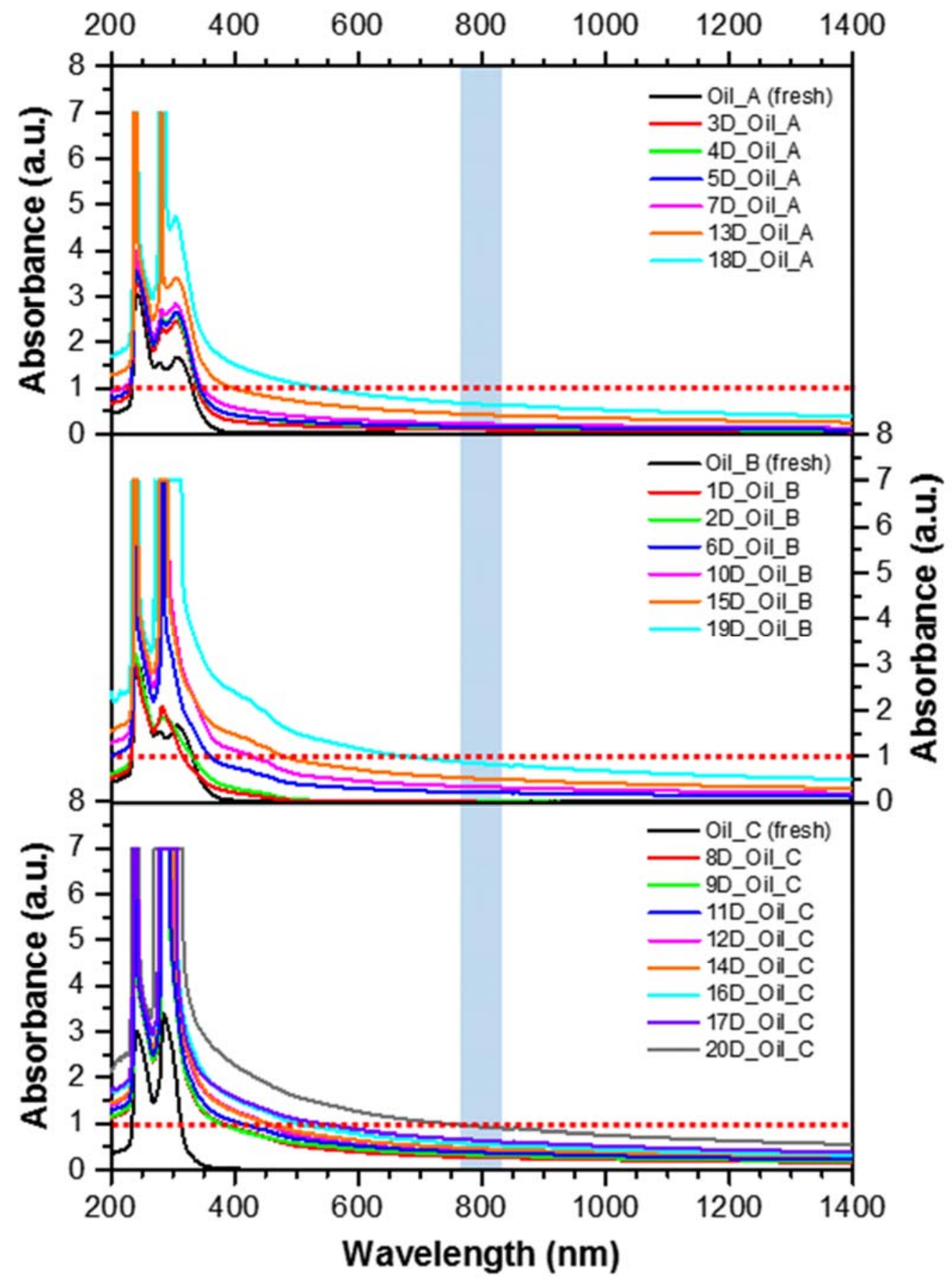

Figure 10: UV-Vis of diluted real samples from diesel engine oil prepared at a 1/135 diluted ratio. The diluted samples are done to reduce its soot concentration to allow to follow the dilution effect with the UV-Vis spectrophotometer. 


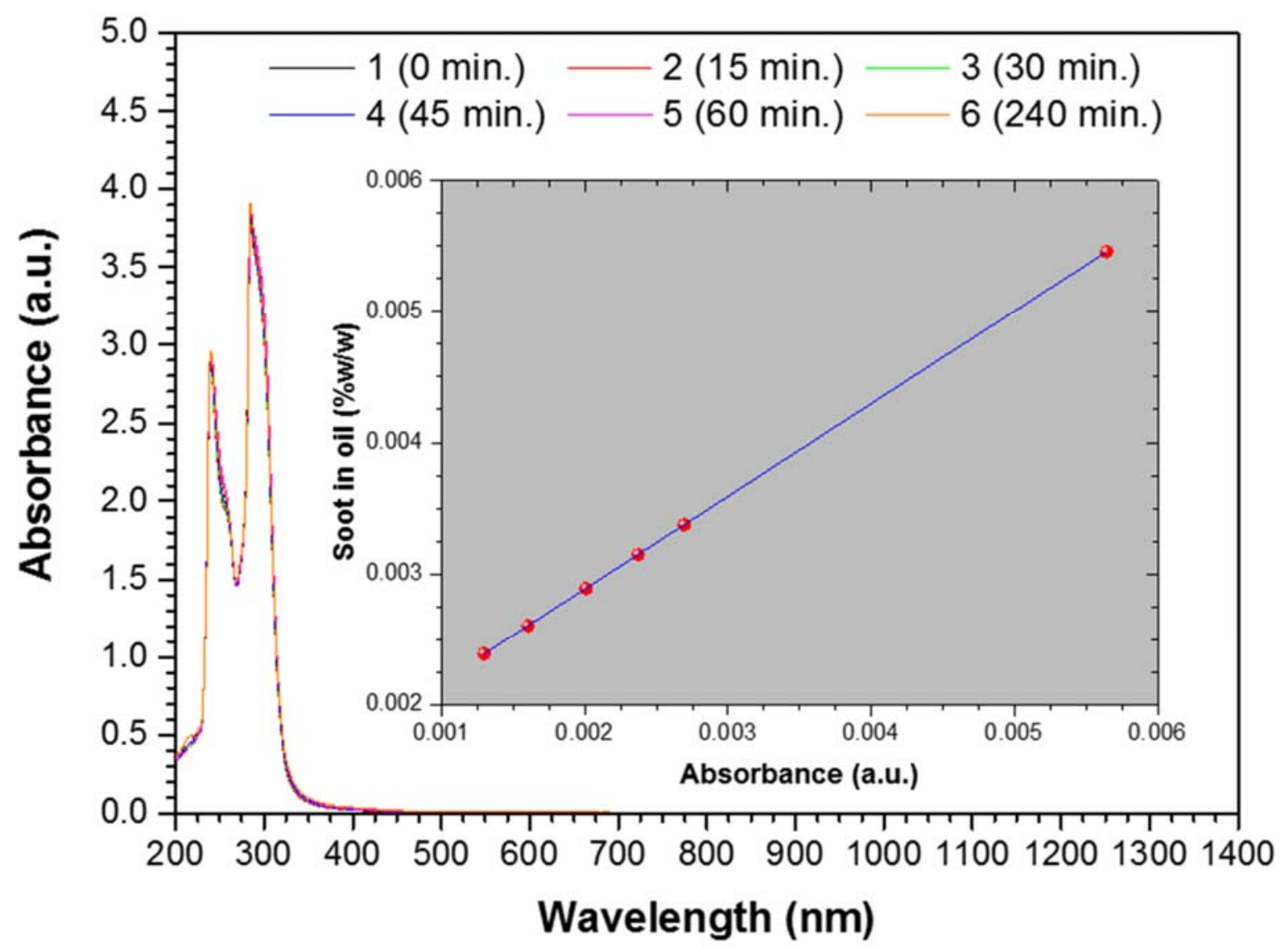

Figure 11: UV-Vis of low mileage diesel engine oil samples. This plot shows that all spectra are very similar but at $800 \mathrm{~nm}$ the absorbance value of each sample is different. Employing the absorbance value at $800 \mathrm{~nm}$ and the empirical correlation 2 it is possible to obtain the soot content of each one. 